\title{
Simulated Effects of Reflective Mulch on Energy and Water Conservation in Semi-Arid Central California Greenhouses
}

\author{
T. Mehlitz and I. Yildiz \\ Department of BioResource and \\ Agricultural Engineering \\ California Polytechnic State University \\ San Luis Obispo, CA 93407 \\ C. Hardin \\ USA \\ USA \\ S. Rahman \\ Department of Civil and Environmental Engineering \\ California Polytechnic State University \\ San Luis Obispo, CA 93407 \\ USA
}

Department of Mechanical Engineering

California Polytechnic State University

San Luis Obispo, CA 93407

Keywords: energy conservation, water conservation, transpiration, reflective mulch, passive heating and cooling

\begin{abstract}
In addition to the labor, energy and water consumption are the two main cost drivers in current greenhouse systems. Consequently, considerable effort is expended to conserve energy and water, and look for alternative energy sources. Greenhouses in hot and arid regions also require large quantities of water for irrigation. Proper environmental management systems can significantly change the energy and moisture dynamics of greenhouse production systems. This study aims to focus on reducing energy and water consumption in semi-arid California greenhouses. Influences of mulch (having different reflectivities) on energy and water conservation were investigated. The reflectivity of mulch used as a floor cover affects the radiation distribution within the canopy stand, eventually affecting the overall energy and water consumption. A dynamic computer simulation model was used to compare different mulch reflectivities, plant heights, and leaf dimensions to draw a conclusion about energy and water conservation. The results showed that using mulch with less reflectivity (for instance, $20 \%$ instead of $80 \%$ ) reduced energy consumption by as much as $4.2 \%$. With a decrease in reflectivity, the absorptivity of the mulch increases consequently. A high absorptivity results in higher rates of solar energy being absorbed during the day, and released during the night. The mulch functions as a collection device, while the floor itself being the thermal mass. By increasing the reflectivity from $20 \%$ to $80 \%$, water savings of up to $8.6 \%$ occurred. The savings in energy consumption, therefore, always have to be seen in conjunction with the water consumption. Also, the effect of reflective mulch fades away as shade from canopy stand increases. A complete system analysis is necessary to obtain a complete energy and water balance and to be able to make a viable conclusion.
\end{abstract}

\section{INTRODUCTION}

The California greenhouse industry is the largest in the U.S. with an area under glass, plastic or other protection over 5,000 acres accounting over $20 \%$ of all U.S. greenhouses (USDA, 2002). California's Gross Cash Income from the greenhouse, nursery and floriculture industry reached 3.3 billion dollars (California Department of Food and Agriculture, 2005). One major factor hindering future expansion of this industry, however, is the cost required to provide environmental control. Large energy costs are frequently incurred to maintain the required thermal and radiant environments in greenhouses during both winter and summer seasons. Consequently, considerable effort is expended to conserve energy and look for alternative energy sources, especially environmentally friendly renewable energy sources and technologies. Greenhouses in hot 
and arid regions also require large quantities of water for irrigation. Proper environmental management systems can significantly change the energy and moisture dynamics of greenhouse production systems.

To provide economically optimal microenvironments for plant growth, designers and operators can choose from different types of mulch materials for covering the floor surface. The reflectivity of the mulch might play an important role for energy and water conservation, and might have an influence on the plant growth. Reflective mulching was reported to alter crop environmental factors by increasing the light intensity by the reflection of incoming light (Roberts and Anderson, 1994), reducing the soil temperature (Brown et al., 1992; Schalk and Robbins, 1987) and increasing the air temperature above the reflective surface (Zalom, 1981). A dynamic simulation model was developed and validated to provide an accurate prediction of greenhouse energy and moisture exchanges as a function of dynamic environmental factors (Yildiz and Stombaugh, 2006). This model was used to predict energy and water consumption using mulch with different reflectivities, plant heights and leaf dimensions.

\section{MATERIALS AND METHODS}

\section{Weather File}

January, April, and July weather files for San Luis Obispo ( $35^{\circ} 17^{\prime} \mathrm{N}$ and $120^{\circ} 39^{\prime}$ W), California, USA were used to represent winter, spring, and summer in the simulations. Simulations were performed starting at the beginning of the fifth day and ended at the end of $29^{\text {th }}$ day of the month providing 25-day simulations. All simulations were performed for the years 2005, 2006 and 2007.

\section{Energy and Mass Balances}

The details of energy and moisture balances of the plant leaves, and the operational and control system characteristics were previously reported by Yildiz and Stombaugh (2006). It should however be emphasized that stomatal resistance to water vapor in this study was defined only as a function of solar radiation, as explained by Yang et al. (1989). It is also worthwhile to provide a summary of energy and mass balances of other components in this article as well. In dealing with the energy and mass exchanges of the structural cover, for instance, it was assumed that the exchanges occurred homogeneously on the cover, and that the heat storage capacity of the cover material was small compared to the existing fluxes, and no condensation or evaporation occurred on or from the cover. It was also assumed that the floor was covered with a polyethylene film providing different floor reflectivities; however, a bare soil option was also provided. A one-dimensional heat conduction equation was used in dealing with the energy balance of the greenhouse floor, by dividing the floor into three layers $(0.01,0.10$ and $0.50 \mathrm{~m})$ with the assumption of homogeneous thermal and hydraulic properties within each layer (Arinze, 1984; Avissar and Mahrer, 1982; Kindelan, 1980). It was also assumed that no condensation or evaporation occurred on or from the floor surface.

The solar radiation was treated by splitting it into direct, diffuse, and scattered components and assuming that all the radiation reflected by and/or transmitted through foliage elements contributed only to the diffuse component. The expression widely used in microclimatological studies for the penetration function of direct solar radiation for uniformly distributed plant canopies was expanded to a row plant stand whose foliage area distribution varied both vertically and horizontally. It was assumed that the scattering distributions (both upward and downward) were uniform horizontally.

A resistance concept was used in dealing with the thermal radiation as outlined by Incropera and DeWitt (1985). A parallel plane analysis was employed whenever it was applicable. For the other cases, a complex multiple surface radiation exchange analysis using the same approach (resistance concept) was employed. 


\section{Greenhouse Characteristics and Analysis}

In this study, a conventional greenhouse system was used, having a natural gas fired furnace, an evaporative cooling system, and a variable shading system. Table 1 shows the greenhouse and the crop characteristics used in this study. To draw a conclusion about energy consumption with respect to mulch reflectivity, four reflectivities were used in this study (Table 1). Assuming that the reflectivity and transmissivity of a specific material is 20 and zero percent, respectively, concludes that the absorptivity of the same material is $80 \%$. The effect of floor surface reflectivity was studied together with four plant heights and three leaf dimension sets (Table 1). All possible combinations of the above treatments for the three years and three seasons were studied, resulting in a total of 432 simulation runs. Daily Mean values for the energy consumption for heating, and the water consumption for transpiration were determined for every season, every year and every treatment. The simulation treatments were compared using standard Analysis of Variance (ANOVA) (significance level of $\mathrm{P}<0.05$ ). Tukey Simultaneous Test at a confidence level of $95 \%$ was performed to compare the means between the treatments, and statistically significant differences were found.

\section{RESULTS AND DISCUSSION}

\section{Energy Consumption for Heating}

The mean energy consumption for heating (of three years) differed with the season and different reflectivities. The colder the outside weather condition was, the more heating energy was needed (i.e., winter the most, summer the least). The higher the reflectivity was, the more energy was needed (i.e., $20 \%$ the least, $80 \%$ the most) (Figs. 1$3 \mathrm{~A}$ ). At a reflectivity level of $20 \%$, the mean energy uses for heating were $32.05,25.39$, and $13.17 \mathrm{MJ} / \mathrm{m}^{2} /$ day for winter, spring, and summer, respectively. At a reflectivity level of $40 \%$, the mean energy uses for heating were $32.65,25.95$ and $13.52 \mathrm{MJ} / \mathrm{m}^{2} /$ day for winter, spring and summer, respectively. At a reflectivity level of $60 \%$, the mean energy uses for heating were $32.91,26.20$ and $13.59 \mathrm{MJ} / \mathrm{m}^{2} /$ day for winter, spring, and summer, respectively. At a reflectivity level of $80 \%$, however, the mean energy consumptions for heating were $33.07,26.51$ and $13.79 \mathrm{MJ} / \mathrm{m}^{2} /$ day for winter, spring, and summer, respectively. Statistical comparisons between all possible pairs were conducted using the Tukey Simultaneous Test at a 95\% confidence level. Table 2 shows that all of the presented means were statistically different from each other. The results reflected the expectations; as the reflectivity increases, the absorptivity decreases. The absorptivity of the floor surface is an important factor which affects the greenhouse environment, because the ground acts as thermal mass. The higher the absorptivity, the more heat can be stored during the day and released whenever needed and especially at night. As a result, the total supplemental heating needed decreases.

Not only the reflectivity, but also the plant height and the leaf dimensions were accountable for energy consumption. The most energy was needed when the plant stands were still short $(0.5-1.0 \mathrm{~m})$. As the plants grew, energy needs for heating went down significantly, depending on the season and final plant height (Figs. 1-3A). The energy consumption also depended on the leaf dimensions, and increased linearly with decreasing leaf area (Figs. 1-3A). These results are valuable to estimate different energy consumptions for specific plants, but are less important given that a greenhouse operator or designer usually has no choice which crop to grow with respect to energy consumption. However, this study showed that a greenhouse with tall plants with small leaves had significantly less heating demand than a greenhouse with small plants with larger leaves (Figs. 1-3A). This was because the taller plants had much less outer surface area exposed to radiation exchange. Due to the space limitation, it was not possible to present the extensive findings of interactions between different variables.

One of the main factors on the energy consumption was the outside weather condition. The presented study was executed using weather data from three different years $(2005,2006$ and 2007). Differences between the years were statistically significant 
as well, and varied depending on the season. The colder the outside weather condition was, obviously the more energy was needed for heating. For the winter and spring data sets, the energy consumption increased over the years, meaning that the year 2006 was colder than 2005; and the year 2007 was even colder than 2006. The summer data proved that the coldest summer was in the year 2005 , followed by a very warm summer in 2006 , and then, relatively speaking, another cold summer in 2007 (Figs. 1-3A).

\section{Water Use for Transpiration}

Yildiz and Stombaugh (2006) reported that the model used in this study consistently overestimated $(\sim 7 \%)$ the daytime inside relative humidities while underestimating $(\sim 10 \%)$ at night. This was due the fact that the stomatal resistance was derived from daytime data only, not counting for the effects of climatic variables other than solar radiation. Since the nighttime transpiration rates account for a very small portion of the total transpiration, the absolute magnitude of the error at night was not significant. Predicted and measured air and leaf temperatures were also in fairly good agreement. The predicted air temperatures were slightly lower than the measured temperatures. The water consumption in this study decreased as mulch reflectivity increased (i.e., $20 \%$ the most, $80 \%$ the least water consumption) (Figs. 1-3B). At a reflectivity level of $20 \%$, the mean water consumption for transpiration (of three years) was $2.49,2.51$ and $2.43 \mathrm{~kg} / \mathrm{m}^{2} /$ day for winter, spring, and summer, respectively. Due to different operating conditions and the control system activated accordingly, it was hard to make conclusions about the rates occurred in different seasons. At a reflectivity level of $40 \%$, the mean water consumption for transpiration was $2.45,2.45$ and $2.36 \mathrm{~kg} / \mathrm{m}^{2} /$ day for winter, spring, and summer, respectively. At a reflectivity level of $60 \%$, the mean water consumption for transpiration was $2.44,2.44$ and $2.36 \mathrm{~kg} / \mathrm{m}^{2} /$ day for winter, spring, and summer, respectively. At a reflectivity level of $80 \%$, the mean water consumption for transpiration was $2.43,2.41$ and $2.22 \mathrm{~kg} / \mathrm{m}^{2} /$ day for winter, spring, and summer, respectively. Summer means show that less transpiration occurred in summer due to higher air moisture levels maintained inside compared to those in winter and spring. Comparisons between all possible pairs were also performed using the Tukey Simultaneous Test at a confidence level of $95 \%$. All of the presented means for winter and spring were statistically different from each other. However, for the summer data set, the reflectivity pairs of $20 \%$ to $40 \%$ and $60 \%$ and $40 \%$ to $60 \%$ were not statistically different (Table 2). As the reflectivity dropped, transpiration rates increased. This was due to the fact that the floor absorbed more incoming solar radiation, and this resulted in higher air temperatures and higher vapor pressure deficits within the lower canopy layers. Our findings were in agreement with the previously reported work (Brown et al., 1992; Roberts and Anderson, 1994; Schalk and Robbins, 1987; Zalom, 1981). The plant heights and leaf dimensions also played an important role with respect to the water consumption for transpiration. In general, the smaller the plants and the larger the leaves were, the less water was consumed (interactions not shown in the article). Different weather conditions represented by the three different years had a major impact on the water consumption, showing that the colder the outside weather conditions were, the more water was consumed for transpiration. This was because colder outside air ventilation resulted in higher vapor pressure deficits inside increasing the transpiration rates as a consequence. Also, Figures 2B and 3B show that spring and summer seasons in 2006 had less transpiration compared to those in the other two years. This was because the year 2006 had moister spring and summer seasons.

\section{CONCLUSION}

This study showed that the energy consumption was dependent on the reflectivity of the mulch (soil) used in the greenhouse. The higher the reflectivity was, the more energy was consumed. A sophisticated design or modification of greenhouses using a specific kind of mulch can therefore save energy during the operational phase of the greenhouse. It seemed that using mulch with a reflectivity of $20 \%$ instead of $80 \%$ could 
save as high as $4.2 \%$ energy. The water consumption for transpiration was also dependent on the reflectivity, but vice versa compared to the energy consumption pattern. This study also showed that significant savings in water consumption (as much as $8.6 \%$ ) could be realized if $80 \%$ reflective mulch was used rather than $20 \%$ reflective one. Even though the model overestimated the daytime inside relative humidity levels, the overestimation applies to all the simulations; hence the savings in water consumption is still valid. However, the effect of mulch on water use faded away as shade from canopy stand increased. To be able to make a conclusion about total energy and water consumption, the greenhouse has to be seen as a complete system. Potential energy savings due to lower reflectivity have to be seen in conjunction with a larger amount of water use. A total energy and water conservation analysis has to be performed for each case separately, considering the specific infrastructure, local water and energy prices, and the crop type.

\section{ACKNOWLEDGEMENTS}

This study was made possible by a grant from the Cal Poly Honors Program. The authors would like to extend their appreciation to BioResource and Agricultural Engineering, and Mechanical Engineering Departments for providing partial funding.

\section{Literature Cited}

Arinze, E.A., Schoenau, G.J. and Besant, R.W. 1984. A dynamic thermal performance simulation model of an energy conserving greenhouse with thermal storage. Transactions of the ASAE 27:508-519.

Avissar, R. and Mahrer, Y. 1982. Verification study of a numerical greenhouse microclimate model. Transactions of the ASAE 25:1711-1720.

Brown, J.E. et al. 1992. Plastic mulch color inconsistently affects yield and earliness of tomato. HortScience 27:1135.

California Department of Food and Agriculture. 2005. California Agricultural Overview California Agricultural Resource Directory.

Incropera, F.P. and DeWitt, D.P. 1985. Introduction to Heat Transfer. John Wiley \& Sons, Inc. New York, USA.

Kindelan, M. 1980. A dynamic modeling of greenhouse environment. Transactions of the ASAE 23(5):1232-1239.

Roberts, B.W. and Anderson, J.A. 1994. Canopy shade and soil mulch affect yield and solar injury of bell pepper. HortScience 29:258-260.

Schalk, J.M. and Robbins, M.L. 1987. Reflective mulches influences plant survival, production and insect control on fall tomatoes. HortScience 22:30-32.

USDA. "2002 Census of Agriculture - State Data (California)", National Agricultural Statistics Service.

Yang, X., Short, T.H., Fox, R.D. and Bauerle, W.L. 1989. The microclimate and transpiration of a greenhouse cucumber crop. Trans. of the ASAE 32(6):2143-2150.

Yildiz, I. and Stombaugh, D.P. 2006. Dynamic modeling of microclimate and environmental control strategies in a greenhouse coupled with a heat pump system. Acta Hort. 718:331-340.

Zalom, F.G. 1981. Effects of aluminum mulch on fecundity of apterous Myzus persicae on heat lettuce in a field planting. Ent. Exp. and Appl. 30:227-230. 


\section{$\underline{\text { Tables }}$}

Table 1. Greenhouse and crop characteristics used in the simulation model.

\begin{tabular}{ll} 
Greenhouse length & $15.0 \mathrm{~m}$ \\
Greenhouse width & $7.50 \mathrm{~m}$ \\
Greenhouse height at eaves & $2.50 \mathrm{~m}$ \\
Greenhouse height at ridges & $4.50 \mathrm{~m}$ \\
Glazing & Double polyethylene \\
Floor surface material & Mulches with a reflectivity of $20,40,60$ or $80 \%$ \\
Crop type & Cucumber \\
Crop row orientation & North - South \\
Distance between plant rows & $0.75 \mathrm{~m}$ \\
Avg. leaf length x width & Set $1: 0.30 \mathrm{x} 0.25 \mathrm{~m}$, Set $2: 0.23 \times 0.18 \mathrm{~m}$, Set 3: \\
& $0.15 \times 0.10 \mathrm{~m}$ \\
Avg. plant height & $0.5 \mathrm{~m}, 0.75 \mathrm{~m}, 1.0 \mathrm{~m}, 1.5 \mathrm{~m}, 2.0 \mathrm{~m}$ \\
\hline
\end{tabular}

Table 2. Comparisons of energy and water consumption means with respect to different mulch reflectivities using the Tukey Simultaneous Test at a 95\% confidence level.

\begin{tabular}{|c|c|c|c|c|}
\hline & \multicolumn{4}{|c|}{ Energy use (all values in $\mathrm{MJ} / \mathrm{m}^{2} /$ day) } \\
\hline & $\begin{array}{l}\text { Reflectivity } \\
\text { (Mean) }\end{array}$ & $\begin{array}{l}\text { Compared to } \\
\text { Reflectivity } \\
\text { (Mean) }\end{array}$ & $\begin{array}{c}\text { Difference of } \\
\text { Means }\end{array}$ & $\begin{array}{c}\text { Statistically } \\
\text { Significant at a } \\
95 \% \text { level? }\end{array}$ \\
\hline \multirow{6}{*}{ 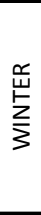 } & \multirow{3}{*}{$0.2(32.05)$} & $0.4(32.65)$ & 0.6 & YES \\
\hline & & $0.6(32.91)$ & 0.86 & YES \\
\hline & & $0.8(33.07)$ & 1.02 & YES \\
\hline & \multirow{2}{*}{$0.4(32.65)$} & $0.6(32.91)$ & 0.26 & YES \\
\hline & & $0.8(33.07)$ & 0.42 & YES \\
\hline & $0.6(32.91)$ & $0.8(33.07)$ & 0.17 & YES \\
\hline \multirow{6}{*}{ 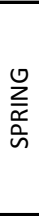 } & \multirow{3}{*}{$0.2(25.39)$} & $0.4(25.95)$ & 0.56 & YES \\
\hline & & $0.6(26.20)$ & 0.8 & YES \\
\hline & & $0.8(26.51)$ & 1.12 & YES \\
\hline & \multirow{2}{*}{$0.4(25.95)$} & $0.6(26.20)$ & 0.25 & YES \\
\hline & & $0.8(26.51)$ & 0.56 & YES \\
\hline & $0.6(26.20)$ & $0.8(26.51)$ & 0.32 & YES \\
\hline \multirow{6}{*}{$\sum_{う}^{\stackrel{\Upsilon}{山}}$} & \multirow{3}{*}{$0.2(13.17)$} & $0.4(13.52)$ & 0.35 & YES \\
\hline & & $0.6(13.59)$ & 0.41 & YES \\
\hline & & $0.8(13.79)$ & 0.62 & YES \\
\hline & \multirow{2}{*}{$0.4(13.52)$} & $0.6(13.59)$ & 0.07 & YES \\
\hline & & $0.8(13.79)$ & 0.27 & YES \\
\hline & $0.6(13.59)$ & $0.8(13.79)$ & 0.21 & YES \\
\hline
\end{tabular}

\begin{tabular}{|c|c|c|c|c|}
\hline & \multicolumn{4}{|c|}{ Water use (all values in $\mathrm{kg} / \mathrm{m}^{2} /$ day) } \\
\hline & $\begin{array}{l}\text { Reflectivity } \\
\text { (Mean) }\end{array}$ & $\begin{array}{c}\text { Compared to } \\
\text { Reflectivity } \\
\text { (Mean) }\end{array}$ & $\begin{array}{c}\text { Difference of } \\
\text { Means }\end{array}$ & $\begin{array}{c}\text { Statistically } \\
\text { Significant at a } \\
95 \% \text { level? }\end{array}$ \\
\hline \multirow{6}{*}{ 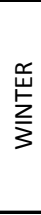 } & \multirow{3}{*}{$0.2(2.49)$} & $0.4(2.45)$ & 0.034 & YES \\
\hline & & $0.6(2.44)$ & 0.046 & YES \\
\hline & & $0.8(2.43)$ & 0.057 & YES \\
\hline & \multirow{2}{*}{$0.4(2.45)$} & $0.6(2.44)$ & 0.011 & YES \\
\hline & & $0.8(2.43)$ & 0.023 & YES \\
\hline & $0.6(2.44)$ & $0.8(2.43)$ & 0.012 & YES \\
\hline \multirow{6}{*}{$\frac{\frac{1}{\infty}}{\frac{1}{n}}$} & \multirow{3}{*}{$0.2(2.509)$} & $0.4(2.45)$ & 0.055 & YES \\
\hline & & $0.6(2.44)$ & 0.074 & YES \\
\hline & & $0.8(2.41)$ & 0.098 & YES \\
\hline & \multirow{2}{*}{$0.4(2.454)$} & $0.6(2.44)$ & 0.019 & YES \\
\hline & & $0.8(2.41)$ & 0.043 & YES \\
\hline & $0.6(2.435)$ & $0.8(2.41)$ & 0.024 & YES \\
\hline \multirow{6}{*}{ 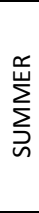 } & \multirow{3}{*}{$0.2(2.433)$} & $0.4(2.36)$ & 0.07 & NO \\
\hline & & $0.6(2.36)$ & 0.072 & NO \\
\hline & & $0.8(2.22)$ & 0.214 & YES \\
\hline & \multirow{2}{*}{$0.4(2.363)$} & $0.6(2.36)$ & 0.002 & $\mathrm{NO}$ \\
\hline & & $0.8(2.22)$ & 0.144 & YES \\
\hline & $0.6(2.361)$ & $0.8(2.22)$ & 0.142 & YES \\
\hline
\end{tabular}




\section{$\underline{\text { Figures }}$}
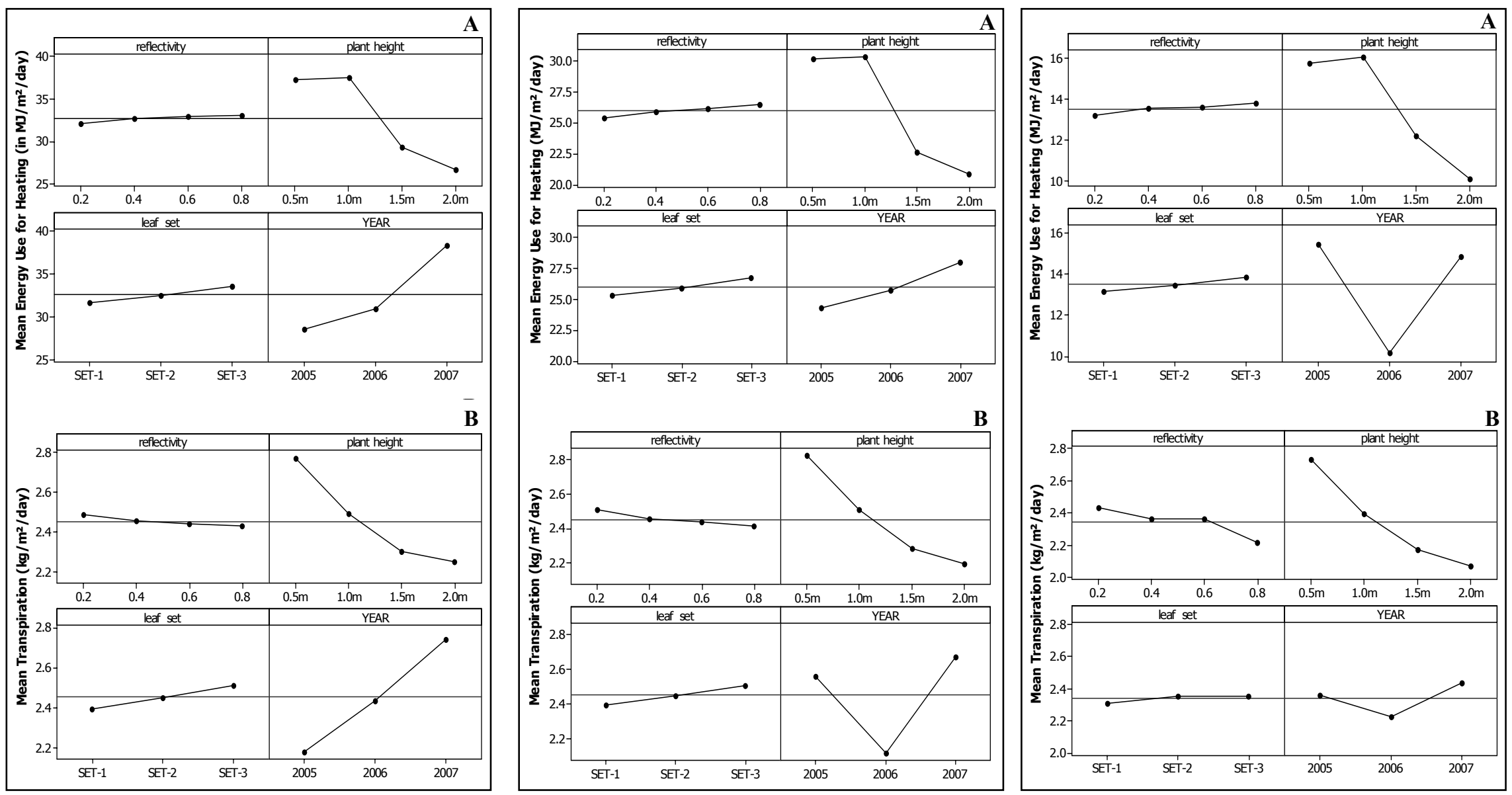

Fig. 1. Main Effects Plot - Energy use for Fig. 2. Main Effects Plot - Energy use for Fig. 3. Main Effects Plot - Energy use for heating (A) and transpiration (B) in winter. Presented are the fitted heating (A) and transpiration (B) in spring. Presented are the fitted heating (A) and transpiration (B) in means. means. 